\title{
REVIEW
}

\section{Treatment modalities for hyperpigmented skin lesions: A brief overview}

\author{
Yan Teng Khoo ${ }^{*}$, Ahmad Sukari Halim ${ }^{2}$ \\ ${ }^{1}$ Beauty with Yan Plastic Surgery Clinic, Kinta Medical Centre, Perak, Malaysia \\ ${ }^{2}$ Reconstructive Sciences Unit, School of Medical Sciences, Health Campus, Universiti Sains Malaysia, Kubang Kerian, Kelantan, Malaysia
}

\begin{abstract}
Skin hyperpigmentation involves a broad range of skin conditions, including epidermal pigmented lesions, dermal pigmented lesions, and mixed pigmented lesions. Treatment includes various modalities such as brightening cream, chemical peeling, and laser therapy. Responses to various treatment modalities can be quite varied depending on the type of treatment and the degree of pigmentation. Sometimes a lesion can lighten or even partially disappear, while other lesions may recur. This paper provides a brief overview of treatment modalities available for hyperpigmented skin lesions including the importance of photoprotection, various types of brightening creams, suitable types of chemical peels, specific laser therapies targeted for skin hyperpigmentation, and surgery.
\end{abstract}

Keywords: skin hyperpigmentation; photoprotection; brightening cream; laser

Citation: Khoo YT, Halim AS. Treatment modalities for hyperpigmented skin lesions: A brief overview. J Surg Dermatol 2022; 7(1): 35; http://dx.doi.org/10.18282/jsd.v7.i1.35.

*Correspondence to: Yan Teng Khoo, Beauty with Yan Plastic Surgery Clinic, Kinta Medical Centre, 20, Jalan Chung Thye Phin, 30250, Ipoh, Perak, Malaysia; beautywithyan@gmail.com

Received: $6^{\text {th }}$ June 2021; Accepted: $29^{\text {th }}$ July 2021; Published Online: $18^{\text {th }}$ August 2021

\section{Introduction}

The management of skin pigmentation disorders poses a significant challenge to both patients and doctors. A doctor's goal to achieve successful elimination of pigmentary lesions rests on two basic principles: 1) minimising detrimental effects of sunlight radiation, and 2) optimising conditions of the pigmentary disorder with available treatment modalities. Although currently available sun protection skin care products are increasingly varied and sophisticated, its primary function remains to reduce the adverse effects of sun radiation.

Skin pigmentation disorders manifest as skin lesions arising from the melanocytic system of the skin. It can be classified as hyperpigmentation lesions (i.e., extrinsic and intrinsic factors imposed on the body that cause excessive pigmentation) or hypopigmentation lesions (i.e., underlying conditions that inhibit pigmentation resulting in decreased melanin production). Pigmentation is the result of melanin pigment production in the melanocytes of the epidermis. Melanin synthesis is stimulated by sunlight and is controlled by the pituitary gland via melanocyte-stimulating hormone (MSH). Melanin synthesis is also influenced by endocrine secretions, including oestrogen and androgen. The number of melanocytes is the same between races; however, the amount of melanin production varies upon stimulation. The melanin in the skin has protective effects from sunlight radiation. The rising trend is that epidermal pigmentation has a direct relationship with the degree of sun exposure. Skin pigmentation affects all ethnic and racial groups; however, skin pigmentation disorders primarily affect fair- skinned populations. The closer the light-skinned races are to the equator, the higher the incidence of skin pigmentation. However, increased pigmentation can be due to causes other than melanin. Table 1 listed the factors that contribute to hyperpigmentation disorders. Treatment modalities of epidermal melanin-induced hyperpigmentation have

Copyright $\odot 2022$ Khoo YT and Halim AS. This is an Open Access article distributed under the terms of the Creative Commons Attribution-Non Commercial 4.0 International License (http://creativecommons.org/licenses/by-nc/4.0/), permitting all non-commercial use, distribution, and reproduction in any medium, provided the original work is properly cited. 
emphasised on not only curative therapy but also preventive measures from sun exposure. The new trend of treating pigmented epidermal lesions has improved exponentially with the advancement of research and development of skin care products and lasers.

Photosensitive pigmentation is commonly localised on areas of the body exposed to the sun, primarily on the face (forehead, cheeks, and upper lip), hands, and back. In darker Asian, and Mediterranean skin types, the appearance of solar lentigines, seborrheic keratosis, and melasma are particularly common. This paper will present a brief overview of the treatment modalities for acquired skin pigmentation.

Table 1. Causes of skin hyperpigmentation

\begin{tabular}{lll}
\hline Causes of increased melanin production & Non-melanin \\
\cline { 1 - 2 } Acquired & $\begin{array}{l}\text { Congenital/ } \\
\text { Inherited }\end{array}$ & causes \\
\hline Melasma & Mongolian spots & Primary \\
Post-inflammatory & Naevus of Ota & haemochromatosis \\
pigmentation & Naevus of Ito & Hepatic cirrhosis \\
Solar lentigines & Spindle cell naevus & Chronic renal \\
Ephelides & Blue naevus & failure \\
Lichen planus & Halo naevus & Alkaptonuria \\
Fixed drug & Café au lait & Lamellar ichthyosis \\
eruption & Peutz-Jegher's & Epidermolytic \\
Erythromelanosis & syndrome & hyperkeratosis \\
follicularis faciei & Albright's syndrome & Drug and heavy \\
et colli & & metal toxicity \\
Pellagra & & Canthaxanthin \\
Poikiloderma of & & Pituitary tumours \\
Civatte & & \\
Riehl's melanosis & & \\
\hline
\end{tabular}

\section{Photoprotection}

Sun protection is of utmost importance in the treatment of skin hyperpigmentation. The use of full spectrum sunscreens should be emphasised before, during, and after procedures. Only sunscreen has a confirmed benefit in the treatment of skin hyperpigmentation. Daily use of sunscreen with a sun protection factor (SPF) of at least 15 is valuable for sun protection. Sunscreen must be applied to all exposed skin including the lips, scalp, and ears. Sunscreen should be applied 15-30 min before sun exposure and reapplied every $2 \mathrm{~h}$. The reapplication of sunscreen is required after swimming or heavy sweating. Outdoor activity during peak tanning or burning hours, between 10 a.m. and 4 p.m., should be minimised or avoided. All patients who are active outdoors should wear additional sun-protective apparel to reduce sunlight radiation exposure. Tanning beds could aggravate skin hyperpigmentation.

\section{Brightening agents}

Topical brightening agents serve a crucial role in achieving the lightening of skin hyperpigmentation. These are composed of natural or synthetic bleaching components which mainly suppress melanocytic activity and help reduce hyperpigmentation. These agents are commonly used as topical products to achieve optimal results after prolonged application. Commonly used brightening agents include hydroquinone, kojic acid, licorice extract, arbutin, ascorbic acid, glycolic acid, niacinamide, azelaic acid, retinoids, and others.

\section{Hydroquinone}

Hydroquinone has the advantage of being well tolerated, easily available with prescription, and inexpensive. These agents are composed of extractions from plants such as tea and coffee, and have an inhibitory effect on tyrosinase which lead to the reduction of melanosomes. Melanocytes are present in the basal layer of the epidermis, producing melanosomes containing melanin which is synthesised from tyrosine with the action of tyrosinase. Hydroquinones are usually combined with tretinoin to achieve optimal depigmentation results. At a concentration of $4 \%-6 \%$, hydroquinone is effective in treating skin hyperpigmentation, including postinflammatory hyperpigmentation, melasma, freckles, age spots, and acne scars. However, prolonged use of hydroquinone (for more than three months) has been associated with exogenous ochronosis (persistent blue-black pigmentation) in Fitzpatrick groups $\mathrm{V}$ and $\mathrm{VI}^{[1]}$.

\section{Kojic acid}

Kojic acid is a type of bleaching agent harvested from Japanese fungus, namely Penicillium and Aspergillus ${ }^{[2]}$. These bleaching agents are mild inhibitors of the formation of pigments in plant and animal tissues, and are used in cosmetics to brighten skin colour. These bleaching agents have a mild inhibitory action on tyrosinase. Kojic acid at a concentration of $4 \%$ or in combination with alpha hydroxy acid (AHA) can cause skin exfoliation to accelerate the lightening result. Kojic acid is used to treat skin disorders such as melasma ${ }^{[3]}$.

\section{Licorice extract}

Licorice is the root of Glycyrrhiza glabra $^{[4]}$. Most 
licorices are used as flavouring agents for tobacco, candies, sweeteners, and herbal medicines. The main component of licorice is glabridin which has been reported to prevent ultraviolet light B-induced skin pigmentation. Clinical trials have demonstrated that licorice has promising tyrosinase inhibition and that it has an influence on both melanogenesis and skin inflammation ${ }^{[5,6]}$. Licorice is very effective in treating post-inflammation hyperpigmentation but it is expensive. Skin hyperpigmentation could be optimised with licorice extract at concentrations ranging from $10 \%-40 \%{ }^{[7]}$. The reduction of hyperpigmentation is also accelerated when licorice extract is combined with kojic acid and vitamin $\mathrm{E}$ in topical applications.

\section{Arbutin}

Arbutin is an extract from a bearberry plant of the genus Arctostaphylos. It is also found in wheat and Bergenia crassifolia $^{[8]}$. Arbutin has a skin-lightening effect by decreasing both tyrosinase activity and melanin content. Hence, it is used in skin-lightening treatments at concentrations of $3 \%-7 \%$ and has been reported to be effective in treating liver spots and freckles ${ }^{[9]}$. Hydroquinone has been banned by the European Committee due to the risks of side effects. Arbutin is an alternative and gentler form of hydroquinone. Arbutin has advantages with long-term usage, and it can be used once or twice daily. In vivo experimental studies have demonstrated that arbutin is a safe and effective brightening treatment for hyperpigmented lesions $^{[9,10]}$.

\section{Ascorbic acid}

Ascorbic acid (vitamin C), derived from fruits and green leafy vegetables, is a type of water-soluble vitamin and is present as a potent antioxidant in human $\operatorname{skin}^{[3,11]}$. Ascorbic acid inhibits melanin synthesis by interfering with the action of tyrosinase. The disadvantages of ascorbic acid are that it is rapidly oxidised, highly unstable, and its hydrophilic property limits its skin penetration $^{[3,12]}$. Hakozaki et al. have demonstrated an enhanced skin-lightening effect by increasing transepidermal penetration and vitamin $\mathrm{C}$ efficacy using ultrasound $^{[13]}$.

\section{Glycolic acid}

Skin-lightening treatments would have more effective results if preceded by thorough exfoliation. Glycolic acid is derived from sugar cane. It is a weak organic acid, and is reportedly effective in treating solar lentigines, melasma, and post-inflammatory hyperpigmentation ${ }^{[14]}$. At low concentrations, it promotes exfoliation of pigmented keratinocytes and facilitates brightening cream penetration. However, any brightening cream treatment must be stopped at least three days prior to chemical peeling treatment to prevent complications such as epidermolysis.

\section{Niacinamide (vitamin $\mathbf{B}_{3}$ )}

Niacinamide is an amide form of vitamin $\mathrm{B}_{3}$ (niacin) and is a water-soluble vitamin. It can be found in trace amounts in fish, nuts, mushrooms, and root vegetables $^{[15,16]}$. Niacinamide has various beneficial medical applications. It has anti-inflammatory actions and may be beneficial to patients with inflammatory skin conditions such as acne vulgaris ${ }^{[17]}$. Hakozaki et al. demonstrated in vitro that niacinamide exhibited effective skin-lightening activity by inhibiting the transfer of melanosomes to adjacent keratinocytes by $35 \%-68 \%{ }^{[18,19]}$. In a clinical study, Navarrete-Solís et al. reported that 8 weeks of treatment with $4 \%$ niacinamide cream showed good to excellent improvement in $44 \%$ of patients with melasma, compared to 55\% from a $4 \%$ hydroquinone cream treatment ${ }^{[20]}$.

\section{Azelaic acid}

Azelaic acid is derived from wheat, rye, and barley. It has been used for treating melasma and postinflammatory hyperpigmentation. It is an alternative to hydroquinone treatment for skin pigmentation. It works as a tyrosinase inhibitor. A clinical study conducted by Breathnach has shown that a topical application of $20 \%$ azelaic acid is superior to $2 \%$ hydroquinone in patients with melasma ${ }^{[1,21]}$. Another clinical trial conducted by Baliña et al. found no significant differences between treating melasma with $20 \%$ azelaic acid cream and $4 \%$ hydroquinone cream. $65 \%$ of patients treated with azelaic acid were reported to have achieved good to excellent results versus $73 \%$ of patients treated with hydroquinone that achieved similar results ${ }^{[22]}$.

\section{Retinoids}

Retinoids are composed of chemical compounds related to vitamin A. It is widely used in medicine, and its beneficial effects are primarily attributed to the regulation of epithelial cell growth. Topical applications of these agents are indicated for dermatological conditions with increased cell turnover such as psoriasis $^{[23]}$ and inflammatory skin disorders such as acne $^{[24]}$. Retinoids are also ideal for treating photoaging and skin wrinkles ${ }^{[25,26]}$. The inhibition of tyrosinase action provides an effective environment for reducing 
hyperpigmentation. Other mechanisms of action include a dispersion of pigmented granules in keratinocytes, a reduction in pigment transfer, and an acceleration of epidermal exfoliation ${ }^{[27]}$. Retinoids are suitable as long-term medications and have favourable safety profiles. When applying topical retinoids, a $0.025 \%$ concentration should be utilised initially as local adverse effects, including erythema, pruritus, and dryness, occur frequently during the early treatment phase ${ }^{[28]}$. Subsequently, treatment can be increased gradually every week up to a daily use of the cream at a concentration of $0.1 \%$. Pathak et al. demonstrated that the treatment of melasma should include a topical formulation of cream containing $2 \%$ hydroquinone and $0.05 \%$ to $0.1 \%$ retinoic $\operatorname{acid}^{[29]}$.

\section{Other active ingredients}

Other ingredients under in vitro investigation include linoleic acid which is an unsaturated fatty acid, extracts from a type of Chilean snail, Helix aspersa, and lumixyl which is a synthetic oligopeptide that exhibits inhibitory activity against human tyrosinase.

\section{Chemical peels}

Chemical peeling is a popular option for facial rejuvenation and treatment of superficial hyperpigmentation. A wide spectrum of chemical peels is available, producing variable effects on the skin. Fine and coarse facial rhytides and uneven skin pigmentations that are not effectively treated surgically can be treated with chemical peels. Chemical peeling affects the epidermis and superficial dermis by smoothing irregularities and altering skin pigmentation. Different solutions are used to target skin injury at specific depths, resulting in the removal of damaged skin with pigmentation. Superficial and medium-depth chemical peels are desirable due to their safety records, effectiveness, relatively low costs, and rapid recovery times. Major indications for chemical peel treatments are solar lentigines and other signs of photodamage including rhytides, scarring, actinic keratosis, melasma, and acne vulgaris. In the early phase of photodamage, skin which exhibits pigmentary changes without wrinkles will respond effectively to repetitive superficial peels $^{[30]}$. Lesions arising from deeper layers of the skin, such as actinic keratosis and melasma, require treatment with one or more medium-depth peels.

All patients should be adequately prepared prior to chemical peeling. Gentle facial washing is required prior to a superficial chemical peel. For medium peels, residual oils, make-up, and debris must be removed thoroughly prior to applying chemical peel solutions. The following discussion will specifically provide an overview of chemical peeling solutions suitable for treating skin hyperpigmentation.

\section{Glycolic acid at $20 \%-70 \%$}

Glycolic acid peels use materials derived from sugarcane. Weekly or biweekly peels using 40\%-70\% unbuffered glycolic acid is a method of superficial peeling. Penetration depth is related to the concentration and duration of the treatment. A patient's skin will naturally develop tolerance to glycolic acid peels. Therefore, a regime should start with a low-strength glycolic peel of $20 \%-30 \%$ applied for 2 min. Patient's level of pain and erythema are the two main factors determining the endpoint of glycolic acid peels. A typical peel regime includes 6 peels with each peel one month apart. At subsequent visits, patient's tolerance to pain and their recovery time can be evaluated. If the patient tolerated the previous glycolic acid peel well, the subsequent peel can be escalated to $40 \%-50 \%$ glycolic acid, or maintained at the same concentration of the previous glycolic acid peel (i.e., 20\%-30\%) and left on the skin longer, for approximately 5-6 min. Glycolic acid peels require dilution with water or neutralisation with $5 \%$ sodium bicarbonate ${ }^{[31]}$. Glycolic acid is found in many cosmetics at low concentrations. A low concentration of glycolic acid may be used as a primer for a chemical peel or for laser resurfacing.

\section{Salicylic acid at $20 \%-30 \%$}

Salicylic acid is a type of beta-hydroxy acid. It has an anti-inflammatory effect and thus helps to diminish inflammation-induced hyperpigmentation. Joshi et al. demonstrated that salicylic acid peels at $20 \%$ to $30 \%$ are safe and clinically effective for patients with Fitzpatrick skin types IV to VI and post-inflammatory hyperpigmentation ${ }^{[32]}$. Salicylic acid peels can remove the stratum corneum and stratum granulosum with an exfoliation process. This will stimulate the generation of new epithelium. Kligman et al. demonstrated that single and multiple salicylic acid peels at $30 \%$ applied at 4-week intervals resulted in significant improvements of pigmentation in patients with moderately photodamaged skin $^{[33]}$.

\section{Blue peel}

Variable results often occur with various chemical peels due to lack of control over the depth of the peel. Trichloroacetic acid (TCA)-based blue peel facilitates the 
treatment of the papillary dermis and immediate reticular dermis. TCA-based blue peel is formed by mixing TCA at a fixed concentration (15\%-20\%) and volume with the blue peel base which contains glycerine, saponins, and a non-ionic blue colour base. This forms a homogenous TCA-oil-water solution for slow penetration and an even coating. An even blue colour demonstrates the uniformity of an application. Hence, the depth of the peel can be easily recognisable. Blue peel has no systemic side effects or toxicity ${ }^{[34]}$.

Frosting occurs as a result of protein denaturation and coagulation. Pink frost develops as the papillary dermis is reached. This will become white frosting as the peel acts at the immediate reticular dermis. The time required for the blue peel solution to begin exerting its action due to initial acid neutralisation by dermal protein is approximately $2 \mathrm{~min}$. Erythema will last for 3-7 days. The use of topical antibiotics and acyclovir should be considered as bacterial and viral infections are common. With increasing peel depth, scarring and pigment change become more likely. A typical regime includes two or three blue peels, and the peels are typically spaced 6-8 weeks apart for maximum effect.

\section{Lasers}

Lasers are based on Einstein's theory of stimulated emission of radiation. In 1960, Theodore Harold Maiman invented and developed light amplification by stimulated emission of radiation (LASER) using a synthetic ruby crystal $^{[35]}$. Maiman's invention led to the subsequent development of various types of lasers. Laser resurfacing removes discolourations, age spots, and photodamaged skin. There are specific lasers for pigmented skin lesions such as lasers with blue, green, red, and near-infrared wavelengths. Various laser systems can be applied to treat skin hyperpigmentation (Table 2). However, lasers should be applied with caution as they will result in paradoxical effect of hyperpigmentation following treatment if no proper information was given to patients.

\section{Continuous wave lasers}

Continuous wave lasers supply an uninterrupted beam of laser light without pulses. Long exposures to these lasers can result in thermal damage to adjacent tissues.

\section{Argon lasers}

An argon laser at a wavelength of $514 \mathrm{~nm}$ produces blue-green light. Continuous wave argon lasers and argon lasers are pulsed using a mechanical shutter target melanin. Therefore, argon lasers have been used in the past to treat port-wine stains and superficial pigmentation ${ }^{[36]}$. However, scarring and depigmentation are commonly observed in argon laser-treated lesions. These unwanted side effects are due to the strong absorption of argon lasers by melanin and the diffusion to surrounding tissues.

Table 2. Various laser resurfacing systems for treating skin hyperpigmentation

\begin{tabular}{lrl}
\hline \multicolumn{1}{c}{ Laser types } & $\begin{array}{r}\text { Wavelength } \\
(\mathrm{nm})\end{array}$ & \multicolumn{1}{c}{ Clinical Applications } \\
\hline $\begin{array}{l}\text { Continuous wave } \\
\text { Argon }\end{array}$ & 514 & $\begin{array}{l}\text { Birthmarks, port wine stains } \\
\text { Flashlight-pumped } \\
\text { pulsed dye (green) }\end{array}$ \\
$\begin{array}{l}\text { Copper vapour } \\
\text { Krypton }\end{array}$ & 510 & $\begin{array}{l}\text { Benign epidermal pigmented } \\
\text { lesions }\end{array}$ \\
KTP:YAG & 520 & $\begin{array}{l}\text { Lentigines } \\
\text { Epidermal pigmented lesions }\end{array}$ \\
CO ${ }_{2}$ (pulsed) & 532 & $\begin{array}{l}\text { Benign pigmented lesions } \\
\text { Various epidermal and dermal } \\
\text { lesions }\end{array}$ \\
Quality-switched (Q-switched) & 10,600 & $\begin{array}{l}\text { Benign pigmented lesions, dark } \\
\text { tattoos }\end{array}$ \\
Ruby & 694 & $\begin{array}{l}\text { Benign pigmented lesions, dark } \\
\text { tattoos }\end{array}$ \\
Alexandrite & 755 & $\begin{array}{l}\text { Pigmented dermal lesions, dark } \\
\text { tattoos }\end{array}$ \\
\hline Nd:YAG & 1,064 \\
\hline
\end{tabular}

\section{Flashlight-pumped pulsed dye lasers (green)}

Flashlight-pumped pulsed dye lasers (green) (FPPDLs) are delivered in short single pulses or a train of pulses at high peak powers. These green-dyed lasers contain fluorescent dyes which are absorbed in water and alcohol. Therefore, the $510 \mathrm{~nm}$ wavelength is absorbed well by melanin, making it suitable for treating benign pigmented skin lesions ${ }^{[36]}$. It penetrates to a depth of $0.75-1.0 \mathrm{~mm}$. In Fitzpatrick V-VI skin, this treatment may damage melanocytes, leading to hypopigmentation.

\section{Copper vapour lasers}

Copper vapour lasers generate light at a wavelength of $511 \mathrm{~nm}$, similar to that of FPPDLs, but the pulses are much shorter at $22 \mathrm{~ns}$ compared with $450 \mu$ s for FPPDLs. These continuous wave copper vapour lasers emit pulses at very high frequencies $(5,000-15,000 \mathrm{~Hz})$. Therefore, these lasers present a higher risk of hypertrophic scarring $^{[37]}$. Copper vapour lasers at $511 \mathrm{~nm}$ have been effective in treating lentigines.

\section{Krypton lasers}

Krypton lasers are a type of continuous wave lasers. 
These lasers emit light at $520 \mathrm{~nm}$ (green) which is effective for treating pigmented epidermal lesions ${ }^{[36]}$. The common problem with krypton lasers is the heating of the skin surface due to strong scattering of light. Hence, skin cooling prior and during this procedure is of utmost importance.

\section{KTP:YAG lasers}

Potassium-titanyl-phosphate (KTP) lasers have a wavelength of $532 \mathrm{~nm}$ which targets melanin. These lasers are effective in treating benign skin hyperpigmentation such as melasma. In cases of melasma, KTP functions by generating gentle heat in melanosomes with long pulses (millisecond) rather than causing mechanical destruction of the target chromophores. KTP lasers greatly reduce redness and pigmentation compared to $\mathrm{Nd}$ :YAG lasers in patients requiring skin rejuvenation ${ }^{[38]}$.

\section{$\mathrm{CO}_{2}$}

The active laser medium is a mixture of carbon dioxide, nitrogen, and helium gases. This combination of gases generates a laser beam with a wavelength of 10,600 nm which is in the middle of the infrared spectrum and is therefore invisible. With a hand piece, the beam is aimed to transmit helium ion light. The target chromophore of the $\mathrm{CO}_{2}$ laser is water. The laser spot is focused at a depth of 0.1-2.0 $\mathrm{mm}$ in the skin, and the specific amount of thermal build-up determines whether the treatment results in ablation, cutting or coagulation at the cellular level. The mainstay of $\mathrm{CO}_{2}$ laser is ablative tissue resurfacing; therefore, it is effective for both benign epidermal and dermal hyperpigmentation such as various benign naevi ${ }^{[39]}$.

\section{Quality-switched (Q-switched) lasers}

When one of the resonating mirrors is non-reflective for an interval of pumping, the stored energy is emitted at extremely high levels of laser energy in a nanosecond. These lasers allow thermal relaxation time; therefore, these lasers carry very little collateral damage to the adjacent tissue and subsequent scarring is rare ${ }^{[40,41]}$. Taylor et al. demonstrated the mechanism of pigment removal via laser application ${ }^{[42]}$. The short pulses of high energy cause rapid thermal expansion of the pigment granules and result in photoacoustic fragmentation of the pigments. These fragments are then removed by redistribution, transepidermal elimination, and phagocytosis ${ }^{[41]}$. The advantages of laser treatment include greater precision, higher efficacy, and lesser scarring than other treatment modalities. However, suspicious pre-malignant and malignant skin lesions are absolute contraindications for laser treatment. Multiple laser treatment sessions are required at 3-4 weeks intervals. Typically, 5 to 6 treatments are performed to achieve noticeable results. Minimal erythema and oedema are commonly noted immediately after laser treatment, and tend to resolve several hours thereafter.

\section{Q-switched ruby lasers}

The ruby laser was the first laser developed. It was initially a continuous wave and was then developed to be Q-switched. Q-switched ruby lasers emit light at a wavelength of $694 \mathrm{~nm}$ which is useful for treating epidermal and dermal pigmented lesions ${ }^{[43]}$.

\section{Q-switched alexandrite}

Alexandrite laser uses a Q-switching system and emits light at a wavelength of $755 \mathrm{~nm}$ which is effective in treating benign pigmented lesions such as freckles ${ }^{[44]}$.

\section{Nd:YAG lasers}

The neodymium: yttrium aluminium garnet (Nd:YAG) laser emits light in the near-infrared band at a wavelength of 1,064 $\mathrm{nm}$. Q-switched Nd:YAG lasers function by a mechanism similar to that of Q-switched ruby lasers. However, it was developed to avoid melanin absorption and further reduce the resulting hypopigmentation that is common with Q-switched ruby laser treatments. It has multiple clinical applications including treating pigmented lesions and tattoos ${ }^{[45-49]}$.

\section{Frequency-doubled Nd:YAG lasers}

When fitted with a K-diphosphate crystal which doubles the frequency and halves the wavelength to $532 \mathrm{~nm}$, Q-switched Nd:YAG lasers are effective in treating epidermal hyperpigmented lesions ${ }^{[43]}$ and red, orange, and yellow tattoos. It is uncommon to have complications with repeated treatments.

Skin preconditioning is an essential part of laser therapy for skin hyperpigmentation. Applications of retinoic acid (vitamin A) with glycolic acid preconditioning regimes are often used before laser resurfacing or chemical peels. These agents increase skin metabolism, accelerate cellular division, boost collagen synthesis, and reduce the thickness of stratum corneum. In doing so, subsequent therapies are more effective. Tretinoin $0.005 \%$ (Renova) is a topical agent that is effective for treating photodamaged skin and mottled pigmentation ${ }^{[50]}$. Pretreatment with retinoids may help to reduce posttreatment hyperpigmentation but it may contribute to 
postoperative erythema. It is also contraindicated during early pregnancy due to its teratogenic effect. Renova is an excellent treatment for solar-induced lentigines on the dorsum of the hands. Overall, laser therapy for skin hyperpigmentation is an expensive consumable.

\section{Surgery}

Surgery is indicated for dermatologic lesions such as large congenital naevus, dysplastic naevi syndrome, melanoma, pre-malignant skin lesions, and malignant skin lesions.

\section{Discussion}

With rapid development of cosmetic products, skin procedures, and medical devices, the desire to have beautiful skin is achievable. Skin rejuvenation can be achieved by improving external appearances without complications. However, there are several important factors that should be taken into consideration in patient evaluation of hyperpigmentation disorders. These include specific skin type, skin complexion based on the Fitzpatrick scale, skin texture, skin thickness, degree of photoaging, severity of facial rhytides, aesthetic outcome, relative cost of treatment, patient expectation, and time consumption.

The purpose of treating hyperpigmentation lesions is to control local factors that result in excessive melanin production. The ideal treatment for hyperpigmentation lesion would achieve this goal by applying the following effects:

1. Eliminate melanin-induced hyperpigmentation;

2. Protect skin against further injury from sun radiation and post-inflammation hyperpigmentation;

3. Reduce oedema and erythema;

4. Promote integrity of the surrounding tissue.

There are numerous medical-grade brightening agents and sun protection agents available. In addition, there are different types of laser therapies available to treat hyperpigmentation disorders. The purpose of treating hyperpigmentation is to develop an optimal treatment that eliminates pigmentary lesions. Non-surgical methods are the most desirable methods. Among non-surgical methods, non-invasive treatments are the most sought after. In contrast with invasive treatments, no downtime is required after non-invasive procedures. Generally, hyperpigmented lesion treatments can be categorised into five groups: 1) photoprotection, 2) topical brightening agents, 3) chemical peeling, 4) laser therapy, and 5) surgery.

\section{Conclusion}

Skin hyperpigmentation is a very common skin disorder in all Fitzpatrick skin types. Various treatment modalities have been studied and have shown improvements in reducing pigmentation. However, no single treatment is effective for all types of dermal hyperpigmentation. A brief overview of the treatment modalities for hyperpigmentation has been provided. Patients with long-standing hyperpigmentation will need to undergo continued treatment depending on the duration of treatment, cost, patients' compliance, and clinicians' experience. Laser treatments and chemical peels remain popular for the treatment of skin hyperpigmentation. These treatments can achieve good synergistic results in combination with brightening creams. Lastly, clinicians should educate patients about the importance of photoprotection to optimise treatment.

\section{Conflict of interest}

The authors declared no potential conflict of interest with respect to the research, authorship, and/or publication of this article.

\section{References}

1. Draelos ZD. Skin lightening preparations and the hydroquinone controversy. Dermatol Ther 2007; 20(5): 308-313. doi:10.1111/j.1529-8019.2007.00144.x.

2. Bentley R. From miso, sake and shoyu to cosmetics: A century of science for kojic acid. Nat Prod Rep 2006; 23(23): 1046-1062. doi: 10.1039/B603758P.

3. Badreshia-Bansal S, Draelos ZD. Insight into skin lightening cosmeceuticals for women of color. J Drugs Dermatol 2007; 6(1): 32-39.

4. Licorice [Internet]. Merriam-Webster's Medical Dictionary: Merriam-Webster, Inc.; 2007 [cited 2015 Dec 1]. Available from: www.merriam-webster.com/dictionary /licorice.

5. Halder RM, Nordlund JJ. Topical treatment of pigmentary disorders. $2^{\text {nd }}$ ed. In: Nordlund JJ, Boissy RE, Hearing VJ, Hearing RA, King WS, et al., (editors). The pigmentary system: physiology and pathophysiology. Oxford: Blackwell Publishing Ltd; 2006. p. 1165-1174. doi: 10.1002/9780470987100.ch59.

6. Picardo M, Carrera M. New and experimental treatments of cloasma and other hypermelanoses. Dermatol Clin 2007; 25(3): 353-362. doi: 10.1016/j.det.2007.04.012.

7. Yokota $\mathrm{T}$, Nishio H, Kubota Y, Mizoguchi M. The inhibitory effect of glabridin from licorice extracts on melanogenesis and inflammation. Pigment Cell Res 1998; 
11(6): 355-361. doi: 10.1111/j.1600-0749.1998.tb0049 4.x.

8. Pop C, Vlase L, Tamas M. Natural resources containing arbutin. Determination of arbutin in the leaves of Bergenia crassifolia (L.) Fritsch acclimated in Romania. Not Bot Hort Agrobot Cluj Napoca 2009; 37(1): 129-132.

9. Boissy RE, Visscher M, DeLong MA. DeoxyArbutin: A novel reversible tyrosinase inhibitor with effective in vivo skin lightening potency. Exp Dermatol 2005; 14(8): 601608. doi: 10.1111/j.0906-6705.2005.00337.x.

10. Hamed SH, Sriwiriyanont P, deLong MA, Visscher MO, Wickett RR, et al. Comparative efficacy and safety of deoxyarbutin, a new tyrosinase-inhibiting agent. J Cosmet Sci 2006; 57(4): 291-308.

11. Colby SI, Schwartzel EH, Huber FJ, Highton A, Altman DJ, et al. A promising new treatment for solar lentigines. J Drugs Dermatol 2003; 2(2): 147-152.

12. Briganti S, Camera E, Picardo M. Chemical and instrumental approaches to treat hyperpigmentation. Pigment Cell Res 2003; 16(2): 101-110. doi: 10.10 34/j.1 600-0749.2003.00029.x.

13. Hakozaki T, Takiwaki H, Miyamoto K, Sato Y, Arase S. Ultrasound enhanced skin-lightening effect of vitamin $\mathrm{C}$ and niacinamide. Skin Res Technol 2006; 12(2): 105-113. doi: 10.1111/j.0909-752X.2006.00186.x.

14. Zhu W, Zhang R. Skin lightening agents. In: Draelos ZD, Thaman LA, (editors). Cosmetic formulation of skin care products. New York: Taylor and Francis Group LLC; 2005. p. 205-218.

15. Zhu W, Gao J. The use of botanical extracts as topical skin-lightening agents for the improvement of skin pigmentation disorders. J Investig Dermatol Symp Proc 2008; 13(1): 20-24. doi: 10.1038/jidsymp.2008.8.

16. Rolfe HM. A review of nicotinamide: Treatment of skin diseases and potential side effects. J Cosmet Dermatol 2014; 13(4): 324-328. doi: 10.1111/jocd.12119.

17. Niren NM. Pharmacologic doses of nicotinamide in the treatment of inflammatory skin conditions: A review. Cutis 2006; 77(1 Suppl): 11-6.

18. Greatens A, Hakozaki T, Koshoffer A, Epstein H, Schwemberger $\mathrm{S}$, et al. Effective inhibition of melanosome transfer to keratinocytes by lectins and niacinamide is reversible. Exp Dermatol 2005; 14(7): 498-508. doi: 10.1111/j.0906-6705.2005.00309.x.

19. Hakozaki T, Minwalla L, Zhuang J, Chhoa M, Matsubara A, et al. The effect of niacinamide on reducing cutaneous pigmentation and suppression of melanosome transfer. $\mathrm{Br}$ J Dermatol 2002; 147(1): 20-31. doi: 10.1046/j.1365-213 3.2002.04834.x.

20. Navarrete-Solís J, Castanedo-Cázares JP, Torres-Álvarez
B, Oros-Ovalle C, Fuentes-Ahumada C, et al. A double-blind, randomized clinical trial of niacinamide $4 \%$ versus hydroquinone $4 \%$ in the treatment of melasma. Dermatol Res Pract 2011; 379173. doi: 10.1155/2011/ 379173.

21. Breathnach AS. Melanin hyperpigmentation of skin: Melasma, topical treatment with azelaic acid, and other therapies. Cutis 1996; 57(1 Suppl): 36-45.

22. Baliña LM, Graupe K. The treatment of melasma $20 \%$ azelaic acid versus $4 \%$ hydroquinone cream. Int $\mathrm{J}$ Dermatol 1991; 30(12): 893-895. doi: 10.1111/j.1365-43 62.1 991.tb04362.x.

23. Saurat JH. Retinoids and psoriasis: Novel issues in retinoid pharmacology and implications for psoriasis treatment. J Am Acad Dermatol 1999; 41(Suppl 3): S2-S6. doi: 10.1016/S0190-9622(99)70358-0.

24. Thielitz A, Gollnick H. Topical retinoids in acne vulgaris. Am J Clin Dermatol 2008; 9(6): 369-381. doi: 10.2165/01 28071-200809060-00003.

25. Stefanaki C, Stratigos A, Katsambas A. Topical retinoids in the treatment of photoaging. J Cosmet Dermatol 2005; 4(2): 130-134. doi: 10.1111/j.1473-2165.2005.40215.x.

26. Mukherjee S, Date A, Patravale V, Korting HC, Roeder A, et al. Retinoids in the treatment of skin aging: An overview of clinical efficacy and safety. Clin Interv Aging 2006; 1(4): 327-348.

27. Nair X, Parah P, Suhr L, Tramposch KM. Combination of 4-hydroxyanisole and all-trans retinoic acid produces synergistic skin depigmentation in swine. $\mathbf{J}$ Invest Dermatol 1993; 101(2): 145-149.

28. Solano F, Briganti S, Picardo M, Ghanem G. Hypopigmenting agents: An updated review on biological, chemical and clinical aspects. Pigment Cell Melanoma Res 2006; 19(6): 550-571. doi: 10.1111/j.1600-0749.200 6.00334.x.

29. Pathak MA, Fizpatrick TB, Kraus EW. Usefulness of retinoic acid in the treatment of melasma. J Am Acad Dermatol 1986; 15(4): 894-899. doi: 10.1016/S0190-962 2(86)70247-8.

30. Glogau RG. Chemical peeling and aging skin. J Geriatr Dermatol 1994; 2: 30-35.

31. Branham GH, Thomas JR. Rejuvenation of the skin surface: Chemical peel and dermabrasion. Facial Plast Surg 1996; 12(2): 125-133. doi: 10.1055/s-0028-1082404.

32. Joshi SS, Boone SL, Alam M, Yoo S, White L, et al. Effectiveness, safety, and effect on quality of life of topical salicylic acid peels for treatment of postinflammatory hyperpigmentation in dark skin. Dermatol Surg 2009; 35(4): 638-644. doi: 10.1111/j.1524-4725.2009.01103.x.

33. Kligman D, Kligman AM. Salicylic acid peels for the 
treatment of photoaging. Dermatol Surg 1998; 24(3): 325-328. doi: 10.1111/j.1524-4725.1998.tb04162.x.

34. Obagi ZE, Obagi S, Alaiti S, Stevens MB. TCA-based blue peel: A standardized procedure with depth control. Dermatol Surg 1999; 25(10): 773-780. doi: 10.1046/j.1524- 4725.1999.98178.x.

35. Low DW, Percec I. Lasers in plastic surgery. In: Thorne $\mathrm{CH}$, Chung KC, Gosain AK, Gurtner GC, Mehrara BJ, et al. (editors). Grabb and Smith's plastic surgery. Philadelphia: Lippincott Williams \& Wilkins; 2013. p.163-172.

36. Goldberg DJ. Laser treatment of pigmented lesions. Dermatol Clin 1997; 15(3): 397-407. doi: 10.1046/j.152 4-4725.1999.98178.x.

37. Chung JH, Koh WS, Lee DY, Lee YS, Eun HC, et al. Copper vapour laser treatment of port-wine stains in brown skin. Australas J Dermatol 1997; 38(1): 15-21. doi: 10.1111/j.1440-0960.1997.tb01092.x.

38. Lee MWC. Combination 532-nm and 1064-nm lasers for noninvasive skin rejuvenation and toning. Arch Dermatol 2003; 139(10): 1265-1276. doi: 10.1001/archderm.139.1 0.1265 .

39. Fitzpatrick RE, Goldman MP, Satur NM, Tope WD. Pulsed carbon dioxide laser resurfacing of photoaged facial skin. Arch Dermatol 1996; 132(4): 395-402. doi: 10.1001/archderm.1996.03890280047007.

40. Reid WH, McLeod PJ, Ritchie A, Ferguson-Pell M. Q-switched ruby laser treatment of black tattoos. Br J Plast Surg 1980; 36(4): 455-459. doi: 10.1016/0007-1226(83)9 0128-5.

41. Laub DR, Yules RB, Arras M, Murray DE, Crowley L, et al. Preliminary histopathological observation of Q-switched ruby laser radiation on dermal tattoo pigment in man. J Surg Res 1968; 8(5): 220-224. doi: 10.1016/0022-4804 (68)90090-5.

42. Taylor CR, Gange RW, Dover JS, Flotte TJ, Gonzalez E, et al. Treatment of tattoos by Q-switched ruby laser: A dose-response study. Arch Dermatol 1990; 126(7): 893899. doi: 10.1001/archderm.1990.01670310055007.

43. Tse Y, Levine VJ, Mcclain SA, Ashinoff R. The removal of cutaneous pigmented lesions with the Q-switched ruby laser and the Q-switched neodymium: yttrium-aluminumgarnet laser. J Dermatol Surg Oncol 1994; 20(12): 795-800. doi: 10.1111/j.1524-4725.1994.tb03707.x.

44. Jang KA, Chung EC, Choi JH, Sung KJ, Moon KC, et al. Successful removal of freckles in Asian skin with a Q-switched alexandrite laser. Dermatol Surg 2000; 26(3): 231-234. doi: 10.1046/j.1524-4725.2000.09243.x.

45. Ross EV, Naseef G, Lin C, Kelly M, Michaud N, et al. Comparison of responses of tattoos to picosecond and nanosecond Q-switched neodymium: YAG lasers. Arch Dermatol 1998; 134(2): 167-171. doi: 10.1001/archderm. 134.2.167.

46. Suzuki H. Treatment of traumatic tattoos with the Qswitched neodymium: YAG laser. Arch Dermatol 1996; 132(10): 1226-1229. doi: 10.1001/archderm.1996.038903 40090014

47. Stratigos AJ, Dover JS, Arndt KA. Laser treatment of pigmented lesions-2000: How far have we gone? Arch Dermatol 2000; 136(7): 915-921. doi: 10.1001/archderm. 136.7.915.

48. Citron BS. Laser treatment of pigmented lesions. Clin Plast Surg 2000; 27(2): 193-198.

49. Kilmer SL. Laser eradication of pigmented lesions and tattoos. Dermatol Clin 2002; 20(1): 37-53. doi: 10.1016/S0733-8635(03)00057-3.

50. Griffiths CEM, Goldfarb MT, Finkel LJ, Roulia V, Bonawitz M, et al. Topical tretinoin (retinoid acid) treatment of hyperpigmented lesions associated with photoaging in Chinese and Japanese patients: A vehiclecontrolled trial. J Am Acad Dermatol 1994; 30(1): 76-84. doi: 10.1016/S0190-9622(94)70011-7. 